\title{
USING STRUCTURAL EQUATION MODELLING TO STUDY THE INFLUENCE OF PERCEIVED USEFULNESS AND PERCEIVED COMPATIBILITY ON STUDENTS' ATTITUDES TOWARDS USING IPAD
}

\author{
Bashar Zogheib \\ American University of Kuwait, Kuwait
}

\begin{abstract}
In this research an attempt has been made to test the integration of constructs from the theoretical models, Technology Acceptance Model (TAM), Innovation Diffusion Theory, Social Cognitive Theory, and Expectation-Confirmation Model in the educational field. It particularly uses Structural Equation Modelling with various constructs to investigate students' acceptance of using IPAD as a technological tool in undergraduate math classes in a Middle Eastern University. The survey in this study contained 150 university students enrolled in various undergraduate math classes at a Middle Eastern private American University, pursuing different fields of study. The empirical results support the theoretical model, it shows the influence of user satisfaction, perceived usefulness and perceived compatibility on students' attitudes towards using IPAD. Students welcomed the adoption of IPAD as a part and tool of the learning process. Finding of this research along with the ongoing research should encourage educators to put more emphasis on using technology in the learning process of mathematics.
\end{abstract}

Keywords: TAM, User satisfaction, Math, IPAD, Educators.

\section{Introduction}

Integration of IPAD in teaching in schools and colleges has been popular in recent years. IPAD is one of the most advanced technologies in the market. It supports hundreds of thousands of applications, many of them related to education (King \& Bass, 2013). According to Khaddage (2013), the touchpad technology use in the education market is dominated by IPAD. Although the pedagogical uses of IPAD is still not clear and the research on the use of the IPAD in education is very recent, many researchers claimed that the advantages of the IPAD overcome its disadvantages. However, the research findings in this area, in the postsecondary education are 
very scarce which is the main reason for conducting this study. Many of these scarce results support the use of tablets in postsecondary education (Kayapinar et al., 2019 \& Bluestein \& Kim, 2017). According to Sachs and Bull (2012) using tablets increases motivation among students and encourages communication and collaboration among students and between teachers and students. Hutchison et al. (2012) reported that using tablets encourages the communication skills among classmates and between students and instructors. It was also reported that tablets have significant positive effect on students with learning problems (McClanahan et al. 2012). This paper aims to investigate the impact of IPAD use on students' attitudes towards using this type of technology in undergraduate math classes. It proposes and empirically tests the integration of constructs from the Theoretical models, Technology Acceptance Model (TAM), Innovation Diffusion Theory, Social Cognitive Theory, and Expectation-Confirmation Model to use IPAD in undergraduate math courses. It aims at investigating and assessing the factors that determine the adoption of technological tools in mathematics among university students. It is believed that the findings of this study will help decision makers in higher education institutions to gain a better understanding of the factors that determine student's adoption of these tools in classrooms and lead to a better implementation, investment, and benefit in the educational field.

Recently, various papers have been published on the context of application of TAM in higher education (Ifinedo, 2019; Zogheib et al., 2015; Teo, 2009, 2010, 2011a, 2011b). A number of studies have used TAM to examine learners' willingness to accept e-learning systems (Al-Adwan et al., 2013; Shah et al., 2013; Sharma and Chandel, 2013; Shroff et al., 2011; Tabak and Nguyen, 2013) or to predict learners' intentions to use an online learning community (Liu et al., 2010). Some papers focused on validating TAM on specific software which is applied in higher education. For example, Escobar-Rodriguez and Monge-Lozano (2012) use TAM for explaining or predicting university students' acceptance of Moodle platform, while Hsu et al. (2009) performed an empirical study to analyze the adoption of statistical software among online MBA students in Taiwan. While some studies report that perceived usefulness and perceived ease of use impact attitude toward technology use and behavioral intention to use technology (Rasimah et al., 2011; Teo, 2011; Sumak et al., 2011), Grandon et al. (2005) argued that e-learning self-efficacy was found to have indirect effect on students' intentions through perceived ease of use. Also, Mungania and Reio (2005) found a significant relationship between dispositional barriers and e-learning self-efficacy. They argued that educational practitioners should take into consideration the learners' dispositions and find ways through which e-learning self-efficacy could be improved. Sumak et al. 
(2011) found that perceived usefulness and perceived ease of use were factors that directly affected students' attitude, and perceived usefulness was the strongest and most significant determinant of students' attitude toward using technology in learning, while Wu and Gao (2011) identified perceived enjoyment as a factor in predicting attitude and behavioral intentions to the use of clickers in student learning. Based on TAM, Wong et al. (2012) explored the role of gender and computer teaching efficacy as external variables in technology acceptance in Malaysia. The authors found that TAM was adequately explained by the data. The model accounted for 36.8 percent of the variance in intention to use computers among student teachers.

\section{Theoretical Frame Work}

\section{Technology Acceptance Model (TAM)}

Among the most popular models in technology acceptance research, the technology acceptance model (TAM) (Davis, 1989) has been found to be a robust and parsimonious model for understanding the factors that affect users' intention to use technology in education (Teo, 2012). In fact, TAM has become one of the most widely used models in technology embedded education research (Kılıç, 2014). What makes the TAM model widespread is its understandability and simplicity (King \& He, 2006).

TAM was developed by Davis (1986) to theorize the usage behavior of computer technology. TAM was derived from another popular theory called Theory of Reasoned Action (TRA) from the field of social psychology which explains a person's behavior through their intentions. Intentions in turn are determined by two constructs: individual attitudes toward the behavior and social norms, or the belief that specific individuals or a specific group would approve or disprove of the behavior. While TRA was developed to explain general human behavior, TAM specifically explains the determinants of computer acceptance that are general and capable of explaining user behavior across a broad range of end-user computing technologies and the user population (Davis et al., 1989). TAM breaks down the TRA's attitude construct into two constructs: perceived usefulness (PU) and perceived ease of use (EU) to explain computer usage behavior. In fact, TAM specifically explains the determinants of information technology end user's behavior towards information technology (Saade' et al., 2007). In TAM, Davis (1989) proposes that the influence of external variables on intention is mediated by perceived ease of use (PEU) and perceived usefulness (PU). TAM also suggests that intention is directly related to actual usage behavior (Davis et al., 1989). 


\section{Innovation Diffusion Theory}

Rogers (2003) defined compatibility as one of the characteristics of innovation. It studies how innovation is perceived as being consistent with the existing values, needs, and past experiences of potential adopters. Past research showed that compatibility demonstrated its pertinence to the discourse on user acceptance of technologies (Chen 2011). TAM was combined with innovation diffusion theory to explain and predict intention to use technologies Chen, et al (2002). Many studies found compatibility as an important factor that affects students' usage of learning technologies (Lai, et al 2012).

\section{The Expectation-Confirmation model}

Satisfaction and perceived usefulness are the major blocks that were defined in the Expectation-Confirmation Model (ECM) which was proposed by Bhattacherjee (2001). Satisfaction refers to the extent to which a user is pleased with using a technology for a particular purpose (Liao, et al 2015). Student satisfaction is an important indicator of the quality of learning experiences students received (Yukselturk \& Yildirim, 2008). Hence, it is valuable to investigate students' satisfaction with different technology used in the learning and teaching process, as new technologies have altered the way in which students interact with instructors and classmates (Kaminski, et al 2009).

Perceived usefulness is defined as the extent to which a person believes that using a particular system will enhance his or her job performance, Davis (1989). Subramanian (1994) found that perceived usefulness had significant correlation with attitude toward usage behavior. This finding was later confirmed by Fu et al. (2006) and Norazah, et al. (2008) who found that behavioral intention was largely driven by perceived usefulness.

\section{Social Cognitive Theory}

Social Cognitive Theory (SCT) states that social and psychosocial factors influence user behavior. Self-efficacy is one of the factors that is considered in this study. It is perceived that is one's belief in his or her ability to execute a task or behavior (Bandura, 1986). Venkatesh and Davis (2000) found that self-efficacy acts as a determinant of perceived ease of use both before and after hands-on use with a system. Self-efficacy is considered as one of the external variables in the TAM model and it plays a vital role in shaping an individual's feeling and behaviour (Compeau \& Higgings, 1995). Research on self-efficacy has been found to be a significant predictor of perceived usefulness and perceived ease of use (e.g., Hsu et al., 2009; Macharia \& Pelser, 2014; Padilla-Melendez et al., 2008). 


\section{Research Model and Hypotheses Development}

The research model of this study is presented in Figure 1. The following hypothesis are proposed based on the theoretical model:

H1: Attitude has a significant effect on students' behavioral intention to use IPAD,

H2: Perceived ease of use has a significant effect on students' attitude towards using IPAD,

H3: Perceived ease of use has a significant effect on the perceived usefulness of IPAD,

H4: Perceived compatibility has a significant effect on attitude towards using IPAD,

H5: Self efficacy has a significant effect on attitude towards using IPAD,

H6: Self efficacy has a significant effect on perceived usefulness towards using IPAD,

H7: Self efficacy has a significant effect on perceived ease of use towards using IPAD,

H8: User Satisfaction has a significant effect on perceived ease of use of IPAD,

H9: User satisfaction has a significant effect on perceived usefulness of using IPAD,

H10: Perceived usefulness has a significant effect on attitude towards using IPAD.

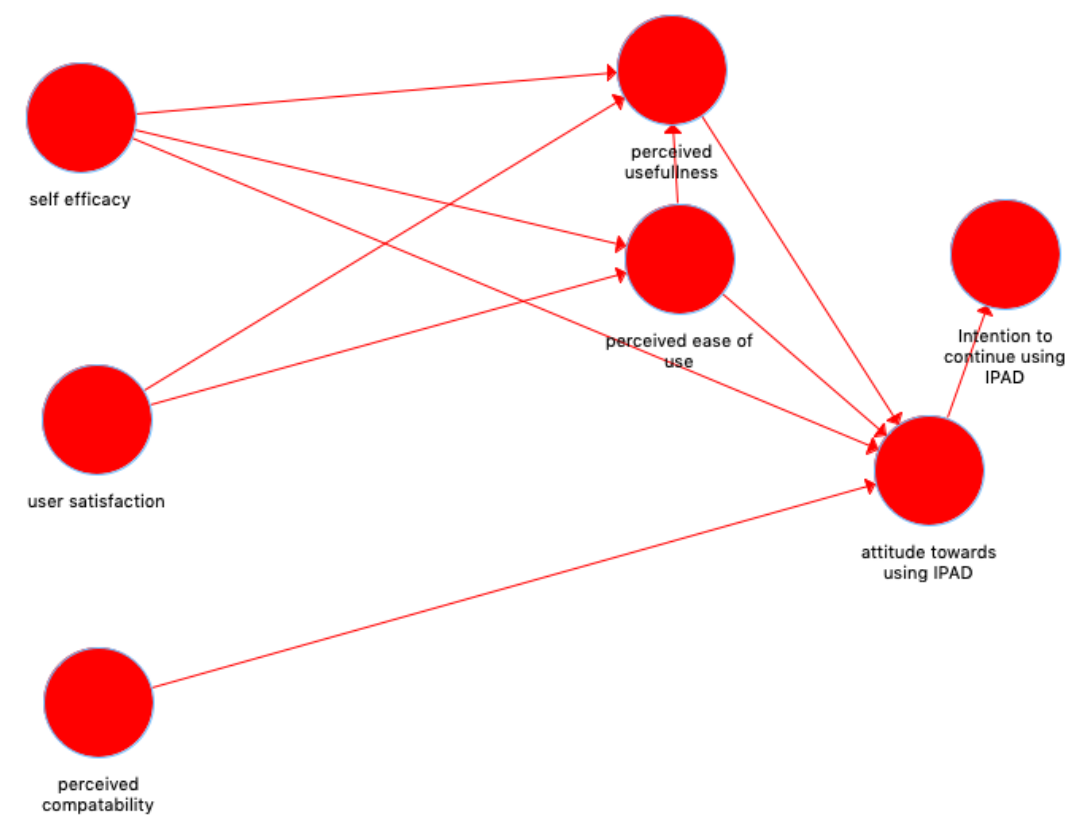

Figure 1. The PLS research model 


\section{Methodology}

\section{Study Context and Participants}

The sample in this study consisted of 150 university students enrolled in undergraduate math classes at a Middle Eastern private American University. The students were enrolled in the academic years 2015-2016 through 2018-2019 in different classes (algebra, calculus, statistics, differential equations...), that were taught by the same instructor. The participants were admitted to the university based on their high school grade point average. Students were pursuing different fields of study, for example, graphic design, communication, business, computer science, engineering, and some were undecided. Many students used IPAD for taking notes and using different math applications.

Data were collected during the last week of classes to guarantee that students had obtained enough experience with the IPAD before they answer the questionnaire questions.

\section{Measures}

The instrument used in this study uses a modified version of the original technology acceptance model (TAM) that was created by Davis (1989). In this study, the combination of TAM and compatibility is used, and constructs were measured by indicators using a 7-point Likert-type scale. The compatibility indicators were "Using IPAD fit well with learning math," "Using IPAD fit well with helping me to be efficient in learning math," "Using IPAD is compatible with my learning math," and "Using IPAD has provided me with a good opportunity to learn math". The behavioral intention indicators were "I intend to check announcements from IPAD frequently," "I intend to be a heavy user of IPAD." The attitude constructs were "studying through IPAD was a good idea," "studying through IPAD was a wise idea," and "I am positive toward IPAD". The perceived usefulness indicators were "IPAD would improve my learning performance," and "IPAD could make it easier to study course content." The perceived ease of use indicators were "I find IPAD system easy to use," "Learning how to use IPAD is easy for me," and "It is easy to become skillful at using IPAD." The satisfaction indicators were "All things considered, I am very satisfied with IPAD," "Over all my interaction with IPAD is very satisfying." The self-efficacy indicators were "I feel confident finding information on Apple webpage," and "I have the necessary skills for using IPAD."

\section{Data Analysis}

The statistical software Smart-PLS 3.1 that implements the use of partial least square structural equation modelling (PLS-SEM) method was used 
to conduct the statistical analysis in this study. (PLS-SEM) is a variancebased method used to estimate structural equation models. Other wellknown softwares such as LISREL and AMOS are covariance based that use the maximum likelihood approach to estimate structural equation models. The advantage of using PLS-SEM lies in the fact that no assumption on the distribution of data is needed (Cassel, et al 1999). Moreover, a sample size that is 10 times the largest number of indicators is required. The large sample size of 150 students will increase the consistency of the model estimations. The indicators in the proposed model are all reflective because they are considered as effects of the latent variables (Bollen and Lennox, 1991).

Tables 1, 2, $3 \& 4$ provide the information on student gender, student age, student years of study and student marital status, respectively.

Table 1. Student gender

\begin{tabular}{|l|c|c|}
\hline & Frequency & Percent \\
\hline Male & 62 & 41.3 \\
\hline Female & 88 & 58.7 \\
\hline Total & 150 & 100 \\
\hline
\end{tabular}

Table 2. Student age

\begin{tabular}{|l|c|c|}
\hline & Frequency & Percent \\
\hline Less than 18 & 15 & 10 \\
\hline $18-25$ & 119 & 79.3 \\
$26-30$ & 6 & 4 \\
More than 30 & 10 & 6.7 \\
\hline Total & 150 & 100 \\
\hline
\end{tabular}

Table 3. Student years of study

\begin{tabular}{|l|c|c|}
\hline & Frequency & Percent \\
\hline one year & 31 & 20.7 \\
\hline Two years & 74 & 49.3 \\
Three years & 21 & 14 \\
Four years & 24 & 16 \\
\hline Total & 150 & 100 \\
\hline
\end{tabular}


Table 4. Student marital status

\begin{tabular}{|l|c|c|}
\hline & Frequency & Percent \\
\hline Single & 116 & 77.3 \\
\hline Married & 34 & 22.7 \\
\hline Total & 150 & 100 \\
\hline
\end{tabular}

In order to assess the measurement model, the composite reliability, convergent validity and discriminant validity should be evaluated (Barclay et al, 1995). The composite reliability estimates the reliability based on the inter correlations of the indicator variables of a specific construct. It is recommended that the value does not exceed 0.95 . Otherwise, the indicators will be measuring same information (Nunally and Bernstein, 1994). Construct reliability for all constructs in the model ranged between 0.910 and 0.951 as shown in Table 5. Convergent validity measures the positive correlation between an indicator and the other indicators of a construct. It can be measured by using the average value extracted measure (AVE) that should exceed 0.5 . Table 6 shows that all values in the model varied between 0.762 and 0.901 . Discriminant validity measures the extent to which a latent variable is distinct from other variables. One way to assess discriminant validity is by using the Fornell-Larcker criterion (Fornell \& Larcker, 1981). It requires that the square root of each construct's (AVE) be higher than all its correlation with the other constructs. Table 7 shows that all diagonal values (square root of AVE) are higher than those in their corresponding rows and columns.

The results of the hypothesis testing are shown in Table 8. Chin (1998) recommended that Bootstrapping of 500 subsamples is to be conducted to test the significant of the $t$ test. Ten hypotheses were tested, a few hypotheses were significant at the 0.05 and 0.1 significance level while the majority were significant at the 0.000 significance level. Table 9 shows the path coefficients and the p-values.

Table 5. Composite Reliability

\begin{tabular}{|l|c|}
\hline & Model \\
\hline attitude (ATT) & 0.932 \\
\hline behavioral intention (BI) & 0.921 \\
\hline perceived ease of use (PE) & 0.910 \\
\hline perceived usefulness (PU) & 0.951 \\
\hline user satisfaction (US) & 0.920 \\
\hline perceived compatibility (PC) & 0.922 \\
\hline self-efficacy (SE) & 0.943 \\
\hline
\end{tabular}


Table 6. Average Value Extracted

\begin{tabular}{|l|l|}
\hline & Model \\
\hline attitude (ATT) & 0.851 \\
\hline behavioral intention (BI) & 0.824 \\
\hline perceived ease of use (PE) & 0.831 \\
\hline perceived usefulness (PU) & 0.901 \\
\hline user satisfaction (US) & 0.762 \\
\hline perceived compatibility (PC) & 0.891 \\
\hline self-efficacy (SE) & 0.878 \\
\hline
\end{tabular}

Table 7. Latent Variable Correlation

\begin{tabular}{|c|c|c|c|c|c|c|c|}
\hline & ATT & BI & PE & PU & US & PC & SE \\
\hline ATT & $\mathbf{0 . 9 2 2}$ & & & & & & \\
\hline BI & 0.505 & $\mathbf{0 . 9 0 8}$ & & & & & \\
\hline PE & 0.773 & 0.444 & $\mathbf{0 . 9 1 2}$ & & & & \\
\hline PU & 0.821 & 0.461 & 0.745 & $\mathbf{0 . 9 4 9}$ & & & \\
\hline US & 0.674 & 0.588 & 0.646 & 0.671 & $\mathbf{0 . 8 7 3}$ & & \\
\hline PC & 0.801 & 0.712 & 0.567 & 0.652 & 0.832 & $\mathbf{0 . 9 4 4}$ & \\
\hline SE & 0.563 & 0.489 & 0.832 & 0.674 & 0.782 & 0.882 & $\mathbf{0 . 9 3 7}$ \\
\hline
\end{tabular}

Table 8. Hypotheses testing results

\begin{tabular}{|c|c|c|}
\hline & Models' coefficients & $\mathrm{P}$ Values \\
\hline H1: ATT -> BI & 0.195 & 0.088 \\
\hline H2: PE - > ATT & 0.147 & 0.086 \\
\hline H3: PE - > PU & 0.323 & 0.012 \\
\hline H4: PC -> ATT & 0.753 & 0.000 \\
\hline H5: SE - > ATT & 0.231 & 0.077 \\
\hline H6: SE -> PU & 0.301 & 0.013 \\
\hline H7: SE - > PE & 0.521 & 0.000 \\
\hline H8: US - > PE & 0.502 & 0.000 \\
\hline H9: US - > PU & 0.535 & 0.000 \\
\hline H10: PU -> ATT & 0.401 & 0.000 \\
\hline
\end{tabular}




\section{Discussion and Conclusion}

This research investigated University students' acceptance of IPAD using the combination of TAM, Innovation Diffusion Theory, Social Cognitive Theory (SCT) and Expectation-Confirmation Model in the educational field. Results revealed that self-efficacy have a positive effect on students' perceived ease of use, perceived usefulness and attitude towards using IPAD. Perceived ease of use is defined as "the degree to which a person believes that engaging in online transactions would be free of effort." For students, this means student's perceived ability to handle technological applications in their math classes. Perceived ease of use affects perceived usefulness and attitude, perceived ease of use affects attitude and attitude affects behavioral intention. The reported results are in line with what is found in literature and can be explained based on the motivational theory (Lee, et al 2005; Saade', et al 2007; Park, 2009). Although the composite reliability values for some of the constructs is close to 0.95 , this is still considered acceptable. High values have been reported in the literature. For example (Yi \& Hwang, 2003) reported values of 0.94 and 0.93 for the two constructs ease of use and enjoyment, respectively. Park (2009) reported a value of 0.93 and 0.94 for perceived ease of use and attitude, respectively. The reason for such high values could be that participants could not fully differentiate between the indicators of the considered construct. This issue could be solved in a future work by probably rephrasing the questions.

Finding of this research should encourage institutions to put more emphasis on implementing more technological tools in the learning process of mathematics. In general, the empirical results supported the model. Probably, students welcomed the adoption of IPAD as a part and tool of the learning process. Perceived usefulness as defined by Davis (1989) is the extent to which a person believes that using a particular system will enhance the job. The high effect of the perceived usefulness construct on attitude can be explained by students' interest in IPAD and viewing it as useful technological tool that might enhance their learning. It seems that students are motivated both intrinsically and extrinsically as they seem to value the role that technological tools will play either on the personal level or on the social level. It is not only beneficial to them as students, but it will also please others, such as parents and educators, to know that such tools had a big influence on their education. Last but not least, this research study examined the applicability of an extended version of TAM to explain students' acceptance of the IPAD as part of their enrolment in mathematics classes at university. The findings have great implications for educators and students all over the world as they shed light on the significant factors that 
determine students' acceptance of technological tools or platforms used in the math classroom.

Despite the great findings of this study, it is essential to remember that it was limited to students in a private American university in the Middle East. It is recommended that same study be done at different institutions in the region, public and private, before any generalization can be made. It is recommended that this study be extended to demographic characteristics, for example, age, gender, location, etc... It would also be interesting to test a variety of technological tools other than IPAD.

\section{References}

Al-Adwan, Am., Al-Adwan, Ah., \& Smedley, J. (2013). Exploring students acceptance of e-learning using Technology Acceptance Model in Jordanian universities. International Journal of Education and Development using Information and Communication Technology, 9(2), 4-18.

Barclay, D., Higgins, C., \& Thompson, R. (1995). The partial least squares (PLS) approach to causal modeling: Personal computer adoption and use as an illustration. Technology studies, 2(2), 285-309.

Bandura, A. 1986. Social Foundations of Thought and Action: A Social Cognitive Theory. Englewood Cliffs, NJ: Prentice-Hall.

Bhattacherjee, A. 2001. "Understanding Information Systems Continuance. An Expectation-Confirmation Model." MIS Quarterly 25 (3): 351-370.

Bluestein, S. A., \& Kim, T. (2017). Expectations and fulfillment of course engagement, gained skills, and non-academic usage of college students utilizing tablets in an undergraduate skills course. Education and Information Technologies, 22(4), 1757-1770.

Bollen, K., \& Lennox, R. (1991). Conventional wisdom on measurement: A structural equation perspective. Psychological bulletin, 110(2), 305.

Cassel, C., Hackl, P., \& Westlund, A. H. (1999). Robustness of partial least-squares method for estimating latent variable quality structures. Journal of applied statistics, 26(4), 435-446.

Chen, J.-L. 2011. "The effects of education compatibility and technological expectancy on e-learning acceptance." Computers \& Education 57: 1501-1511.

Chen, Y. N., H. Lou, and W. Luo. 2002. "Distance learning technology adoption: A Motivation Perspective." Journal of Computer Information Systems 42 (2): 38-43.

Chin, W. W. (1998). The partial least squares approach to structural equation modeling. Modern methods for business research, 295(2), 295-336.

Compeau, D. R., C. A. Higgins, and S. Huff. 1999. "Social Cognitive Theory and individual reactions to computing technology: A Longitudinal Study." MISQ Quarterly 23 (2): 145-158.

Davis, F. D. (1986), "A technology acceptance model for empirically testing new end-user information systems: theory and results", doctoral dissertation, MIT Sloan School of Management, Cambridge, MA. 
Davis, F., (1989), Perceived usefulness, perceived ease of use, and user acceptance of information technology. MIS Quarterly, 13(3), 319-339.

Davis, F. D., Bagozzi, R. P. \& Warshaw, P. R. (1989), User acceptance of computer technology: a comparison of two theoretical models, Management Science, 35(8), 982-1003.

Escobar-Rodriguez, T., \& Monge-Lozano, P. (2012). The acceptance of Moodle technology by business administration students.Computers \& Education, 58, 1085-1093.

Fornell, C., \& Larcker, D. F. (1981). Evaluating structural equation models with unobservable variables and measurement error.Journal of marketing research, 39-50.

Fu, J. R., Farn, C. K., \& Chao, W. P. (2006). Acceptance of electronic tax filing: A study of taxpayer intentions. Information \& Management, 43, 109-126.

Grandon, E., Alshare, O., \& Kwan, O. (2005). Factors influencing student intention to adopt online classes: A cross-cultural study. Journal of Computing Sciences in Colleges, 20(4), 46-56.

Hsu, M. K.., Wang S. W., \& Chiu, K. K. (2009). Computer attitude, statistics anxiety and self-efficacy on statistical software adoption behavior: An empirical study of online MBA learners. Computers in Hu-man Behavior, 25, 412-420.

Hutchison, A., Beschorner, B., \& Schmidt-Crawford, D. (2012). Exploring the use of the iPad for literacy learning. The Reading Teacher, 66(1), 15-23.

Ifinedo, P. (2018). Determinants of students' continuance intention to use blogs to learn: An empirical investigation. Behaviour \& Information Technology, 37(4), 381-392.

Kaminski, K., Switzer, J., \& Gloeckner, G. (2009). Workforce readiness: A study of university students' fluency with information technology. Computers \& Education, 53(2), 228-233.

Kayapinar, U., Erkir, S., \& Kose, N. (2019). The Effect of Tablet Use on Students' Success in English as a Foreign Language (EFL) Grammar Classroom. Educational Research and Reviews, 14(5), 178-189.

Khaddage, F. (2013). The iPad global embrace! Are we branding mobile learning? In R. McBride, \& M. Searson (Eds.), Proceedings of Society for Information Technology \& Teacher Education International Conference 2013 (pp. 3234-3240). Chesapeake, VA: AACE.

Kiliç, E. (2014). Determining the factors of affecting the Moodle use by using TAM. The story of a univer-sity after a destructive earthquake. Hacettepe Üniversitesi Eğitim Fakültesi Dergisi, 29(1), 169-179.

King, I., \& Bass, D. (2013). Microsoft's Surface tablet Is said to fall short of predictions. Retrieved from http://www.bloomberg.com/news/2013-03-14/microsoft-s-surfacetablet-is-said-to-fall-short-ofpredictions.html.

King, W. R. \& He (2006). A meta-analysis of the technology acceptance model. Information \& Management, 43(6), 740-755.

Lai, C., Q. Wang, and J. Lei. 2012. "What factors predict undergraduate students' use of technology for learning? A Case from Hong Kong." Computers \& Education 59: 569-579.

Liao, Y.-W., Y.-M. Huang, and Y.-S. Wang. 2015. "Factors affecting students' continued usage intention toward business simulation games: an empirical study." Journal of Educational Computing Research 53 (2): 260-283. 
Lee, M. K. O., Cheung, C. M. K., \& Chen, Z. (2005). Acceptance of internet-based learning medium: The role of extrinsic and intrinsic motivation. Information \& Management, 42, 1095-1104.

Liu, I. F., Chen, M. C., Sun, Y. S., Wible, D., \& Kuo, C. H. (2010). Extending the TAM model to explore the factors that affect Intention to Use an Online Learning Community. Computers \& Education, 54(2), 600-610.

Macharia, J. K., \& Pelser, T. G. (2014). Key factors that influence the diffusion and infusion of information and communication technologies in Kenyan higher education. Studies in Higher Education, 39(4), 695-709.

McClanahan, B., Williams, K., Kennedy, E., \& Tate, S. (2012). A breakthrough for Josh: How use of an iPad facilitated reading improvement. Techtrends, 56(3), 20-28. doi:10.1007/s11528-012-0572-6.

Mungania, P., \& Reio, T. G., Jr. (2005). If e-learners get there, will they stay? The role of e-learning self-efficacy. Paper presented at the Academy of Human Resource Development International Conference (AHRD), Estes Park, CO, Feb 24-27, 2005, 1110-1117.

Nunnally, J. C., \& Bernstein, I. H. (1994). The assessment of reliability. Psychometric theory, 3, 248-292.

Padilla-Melendez, A., Garrido-Moreno, A., \& Aguila-Obra, A. R. D. (2008). Factors affecting e-collaboration technology use among management students. Computers and Education, 51,609-623.

Norazah, M. S., Ramayah, T., \& Norbayah, M. S. (2008). Internet shopping acceptance: Examining the influence of intrinsic versus extrinsic motivations. Direct Marketing: An International Journal, 2(2), 97-110.

Padilla-Melendez, A., Garrido-Moreno, A., \& Aguila-Obra, A. R. D. (2008). Factors affecting e-collaboration technology use among management students. Computers and Education, 51,609-623.

Park, S. Y. (2009). An analysis of the Technology Acceptance Model in understanding university students' behavioral intention to use e-Learning. Educational Technology \& Society, 12(3), 150-162.

Rasimah, C. M. Y., Ahmad, A., Zaman, H. B. (2011). Evaluation of user acceptance of mixed reality technology. In K. S. Hong \& K. W. Lai (Eds.), ICT for accessible, effective and efficient higher education: Experiences of Southeast Asia. Australasian Journal of Education Technology, 27 (Special issue, 8), 1369-1387.

Rogers, E. M. 2003. Diffusion of Innovations. $5^{\text {th }}$ ed.New York: Free Press.

Saadé, R., Nebebe, F., \& Tan, W. (2007). Viability of the "Technology Acceptance Model" in multimedia learning environments: A comparative study. Interdisciplinary Journal of E-Learning and Learning Objects, 3(1), 175-184. Retrieved from http://www. ijello.org/Volume3/IJKLOv3p175-184Saade393.pdf

Sachs, L., \& Bull, P. (2012, March). Case study: Using iPad2 for a graduate practicum course. In Society for Information Technology \& Teacher Education International Conference (pp. 3054-3059). Association for the Advancement of Computing in Education (AACE).

Shah, S. A. M., Iqbal, N., Janjua, S. Y., \& Amjad, S. (2013). Employee behavior towards adoption of e-learning courses: Validating Technology Acceptance Model. Mediterranean Journal of Social Sciences, 4(14), 765. 
Sharma, S. K., \& Chandel, J. K. (2013). Technology acceptance model for the use of learning through websites among students in Oman. The International Arab Journal of Information Technology, 3(1), 44-49.

Shroff, R. H., Deneen, C. C., \& Ng, E. M. W. (2011). Analysis of the technology acceptance model in examining students' behavioral intention to use an e-portfolio system. Australasian Journal of Educational Technology, 27(4), 600-618.

Subramanian, G. H. (1994), A replication of perceived usefulness and perceived ease of use measurement, Decision sciences, 25(5-6), 863-874.

Sumak B., Hericko M., Pusnik M., \& Polancic G. (2011). Factors affecting acceptance and use of Moodle: An empirical study based on TAM. Informatica, 35, 91-100.

Tabak, F., \& Nguyen, N. T. (2013). Technology acceptance and performance in online learning environments: impact of self-regulation. MERLOT Journal of Online Learning and Teaching, 9(1), 1-11.

Teo, T. (2009). Modelling technology acceptance in education: A study of pre-service teachers. Computers \& Education, 52(2), 302-312.

Teo, T. (2010). An empirical study to validate the Technology Acceptance Model (TAM) in explaining the intention to use technology among educational users. International Journal of Information and Communication Technology Education, 6(4), 1-12.

Teo, T. (2011a). Factors influencing teachers' intention to use technology: Model development and test. Computers \& Education, (57), 2432-2440.

Teo, T. (2011b). Technology Acceptance in Education, Research and Issues. Rotterdam: Sense Publishers.

Teo, T. (2012). Examining the intention to use technology among pre-service teachers: An integration of the Technology Acceptance Model (TAM) and Theory of Planned Behavior (TPB). Interactive Learning Environments, 20(1), 3-18.

Venkatesh, V., \& Davis, F. D. (1996). A model of the antecedents of perceived ease of use: Development and test. Decision Sciences, 27, 451-481.

Wong K. T., Teo T., \& Russo S (2012). Influence of gender and computer teaching efficacy on computer acceptance among Malaysian student teachers: An extended technology acceptance model, Australasian Journal of Education Technology, 28(7), 1190-1207.

Wu, X., \& Gao, Y. (2011). Applying the extended technology acceptance model to the use of clickers in student learning: some evidence from macroeconomics classes. American Journal of Business Education, 4(7), 43-50.

Yukselturk, E., and Z. Yildirim. (2008). Investigation of interaction, online support, course structure and flexibility as the contributing factors to students' satisfaction in an online certificate program. Educational Technology \& Society 11 (4), 51-65.

Zogheib, B., Rabaa'i, A., Zogheib, S., \& Elsaheli, A. (2015). University student perceptions of technology use in mathematics learning. Journal of Information Technology Education, 14. 